\title{
In Vivo Analysis of Prostaglandins-induced Ocular Surface and Periocular Adnexa Modifications in Patients with Glaucoma
}

\author{
SILVIO DI STASO ${ }^{1}$, LUCA AGNIFILI ${ }^{2}$, SARA CECANNECCHIA ${ }^{1}$, \\ ANGELA DI GREGORIO $^{1}$ and MARCO CIANCAGLINI ${ }^{1}$ \\ ${ }^{1}$ Ophthalmology Unit, Department of Life, Health and Environmental Sciences, \\ University of L'Aquila, L'Aquila, Italy; \\ ${ }^{2}$ Ophthalmology Clinic, Department of Medicine and Aging Sciences, \\ University G. d'Annunzio of Chieti-Pescara, Chieti, Italy
}

\begin{abstract}
Background/Aim: Prostaglandin analogues (PGAs) are a first-line medical treatment for glaucoma because of their powerful intraocular pressure (IOP) lowering effect, few systemic side-effects (SEs), and the once daily administration. Despite the high systemic safety profile, the chronic use of PGAs may induce periocular and ocular surface (OS)-related side effects, which affect a significant proportion of glaucomatous patients. In this review, we summarize the current knowledge about SEs of PGAs on periocular structures and $O S$, and their implications in clinical practice. Materials and Methods: A comprehensive literature search on the PubMed platform was performed. Two hundred fifty articles fulfilling key words were identified, of which 180 were excluded since they did not concern the effects of PGAs on the periocular tissues and OS, or because of their limited relevance. The following key words were used and combined, to narrow-down the literature: "prostaglandin" and "ocular surface," which identified 184 unique publications, of which 68 were selected; "prostaglandin" and "periocular" which identified 46 unique publications, of which 11 were selected. An additional search was conducted using "prostaglandin" and "Meibomian glands (MGs)", which identified twenty unique publications, of which 8 were selected. Thus, a total of 70 articles were chosen based on their relevance and were
\end{abstract}

This article is freely accessible online.

Correspondence to: Marco Ciancaglini, Eye Clinic, San Salvatore Hospital, 66100 L'Aquila, Italy. Tel: +39 3499778688, Fax: +39 0854216636, e-mail: marco.ciancaglini@cc.univaq.it

Key Words: Glaucoma, prostaglandin analogues, side effects, adverse events, medical therapy, benzalkonium chloride, in vivo confocal microscopy, review. included in this review. Results: Prostaglandin-associated periorbitopathy, skin pigmentation and hypertrichosis, eyelash growth, and MGs dysfunction are the most frequent modifications of periocular tissues. They are induced by the tissue accumulation of PGAs, and FP receptor stimulation. Without preservatives, PGAs act as stimulators of conjunctival goblet cells, which are the main source of ocular surface mucoproteins, and seem to increase conjunctival epithelium microcysts proposed as in vivo hallmark of the trans-scleral aqueous humour outflow. Additional PGA-induced modifications can be recognized in the cornea, corneo-scleral limbus, conjunctival stroma and, conjunctiva-associated lymphoid tissue, mainly appearing as inflammatory changes. OS epithelia desquamation, chemosis, apoptosis, dendritic cell activation, conjunctival or episcleral vasodilation, and subbasal nerve plexus disruption were also described in patients receiving preserved PGAs. Conclusion: PGAs induce several modifications of the OS structures and adnexa; nonetheless, none of them significantly reduces the local safety profile of this class of drugs. Moreover, the OS changes do not affect the IOP lowering efficacy of PGAs. On these bases, local SEs of PGAs should not discourage clinicians in using this class of medications because of their efficacy, the systemic safety profile, and the better adherence.

Glaucoma is the second leading cause of blindness worldwide and it is the most frequent cause of irreversible blindness (1). The intraocular pressure (IOP) rise, a consequence of outflow structures impairment (2), is the main risk factor for glaucoma. The goal of glaucoma treatment is to maintain the patient's visual function and quality of life, reducing the rate of retinal ganglion cell loss; this result is obtained by lowering the intra-ocular pressure (IOP) with therapy $(3,4)$, while neuroprotective drugs could complement hypotensive therapies $(5,6)$. Prostaglandin 
analogues (PGAs) are a primary medical treatment for glaucoma because of their powerful IOP lowering effect, few systemic adverse reactions, and once daily administration. Despite the safety profile, the chronic use of PGAs induces some adverse reactions around the eyes and on the ocular surface (OS). Some of these changes are thought to be specific side effects of PGA, because they occur with a significant frequency. In addition to in vitro and animal model studies, over the past decade knowledge about the ocular surface in glaucoma has significantly increased with the use of in vivo laser scanning confocal microscopy (IVCM). This method is able to show in vivo modifications at the cellular level of OS and adnexa, induced by antiglaucoma drugs $(7,8)$. In this review, we summarize the current knowledge about the effects of PGAs on periocular tissues and OS and their implications in clinical practice.

\section{Materials and Methods}

A comprehensive literature search on PubMed was performed. Two hundred fifty articles fulfilling key words were identified, of which 180 were excluded since they did not concern the effects of PGAs on the periocular tissues and OS, or because of their limited relevance. The following key words were used and combined, to narrow down the literature: "prostaglandin" and "ocular surface", which identified 184 unique publications, of which 68 were selected; "prostaglandin" and "periocular" which identified 46 unique publications, of which 11 were selected. An additional search was conducted using "prostaglandin" and "Meibomian glands (MGs)", which identified twenty unique publications, of which 8 were selected. Thus, a total of 70 articles were chosen based on their relevance and were included in this review.

\section{Results}

\section{Periocular changes}

Prostaglandin-associated peri-orbitopathy (PAP). The first report about PAP was described in 2004 in bimatoprost users as "deepening of the upper eyelid sulcus (DUES)" (9). The presence of DUES was subsequently observed among users of other PGAs, including travoprost, latanoprost and tafluprost (10-13). The prevalence of DUES is $44 \%$ after at least three months of therapy (14), whereas its incidence ranges from 25 to $60 \%(12,15-17)$ and is significantly higher in patients treated with bimatoprost $(60 \%)$ than with latanoprost and travoprost (6\% and 53\%, respectively) (1214). Bimatoprost-induced DUES is, at least partially, reversible after drug interruption or change: in fact, DUESrelated symptoms reduce or disappear in $85 \%$ of patients after switching from bimatoprost to latanoprost (18). PAP includes other clinical findings besides DUES, that consist in the absence of dermatochalasis, a deep crease and ptosis of the upper eyelid, decreased prominence of the inferior orbital fat pads, enophthalmos, orbital fat atrophy, flattening of the lower eyelid bags, inferior scleral show, tight orbits
$(19,20)$. Besides bimatoprost use, also the travoprost use and the older age were found to be risk factors for PAP (14); on the other hand, the duration of PGA administration and gender, were not associated with PAP development. The mechanism of PAP was initially related to the function of the Muller muscle (9); later, a magnetic resonance imaging study indicated a reduction in orbital adipose tissue after long-term use of PGAs (21), focusing the attention on modification of fat orbital tissue. Recently, the most part of evidences consider PAP as a result of the orbital fat atrophy, deriving from FP receptor stimulation-induced lipolysis and adipogenesis inhibition (22). The different changes in the amount of orbital fat tissue atrophy of PGA sub-types may be explained by the differences in pharmacokinetics, receptor affinity, and mechanisms of action, considering that bimatoprost, which shows the higher incidence of PAP, has a dual mechanism of action since it stimulates both FP and prostamide FP receptors.

Periocular skin changes. The most frequent PGAs induced periocular tissue modifications are represented by skin pigmentation and hypertrichosis. The frequency of eyelid pigmentation was reported to range from 0 to $25.9 \%$, whereas eyelash bristles was reported to occur in $0-77 \%$ of patients (23-30). The wide variation in the frequency of skin changes found in the literature most probably depend on the different duration of therapy, the method used to determine skin changes (slit lamp or images), and race. PGA administration for more than three months is thought to be associated with a higher occurrence of skin changes. In fact, the frequency of eyelid pigmentation and eyelash bristles increase from $1.5-2.9 \%$ and $0-33 \%$, respectively, in patients with $<3$ months of medication use, to $0-25 \% \%$ and $0.7-77 \%$, in patients with more than three months of PGA use. Inoue et al., in a study that compared the effects of the long-term use of different types of PGAs on peri-ocular skin, reported a skin pigmentation in $4-6 \%$ of eyes without significant differences among medications. Interestingly, the authors did not find relations between skin pigmentation and age, gender, administration period, and IOP (31). In contrast, eyelash bristles were found in $26-54 \%$ of the subjects, with a higher frequency in bimatoprost users; moreover, the duration of therapy was significantly shorter for cases in which eyelash bristles appeared (22.5 \pm 25.2 months) compared with those in which they did not appear (30.6 \pm 29.5 months; $p<0.0296)$.

Eyelash growth. Since initial PGA introduction, eyelash growth has been reported to be a frequent side effect of this class of medications. First, Johnstone, in 1997, reported that 43 patients treated with topical monocular latanoprost $0.01 \%$ developed hypertrichosis and pigmentation of the eyelashes (32); later, a change in length and thickness of the eyelashes 

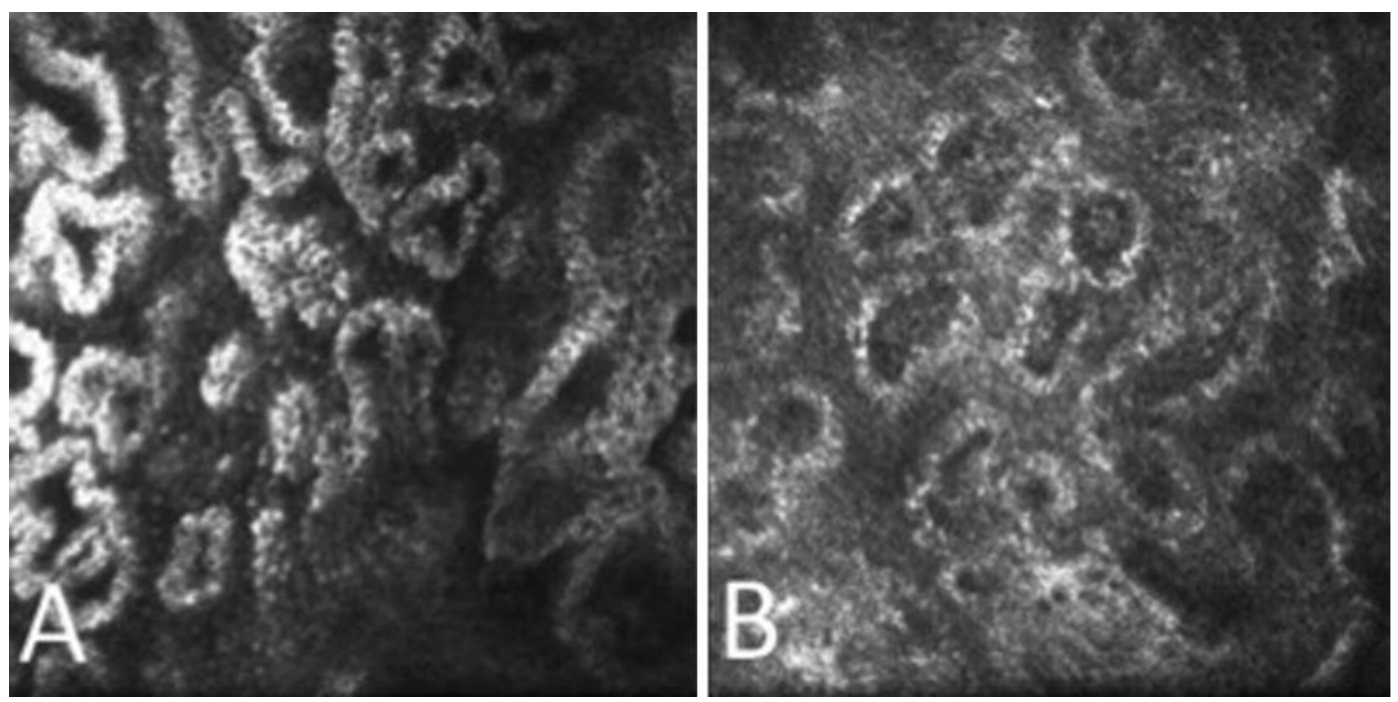

Figure 1. IVCM images of MGs in PF-PGAs (A) and preserved PGAs (B). Acinar unit density and area appeared reduced and meibomian gland secretion was hyper-reflective in preserved PGAs compared to unpreserved PGAs.

was described in $46.3 \%$ of patients treated with latanoprost, without significant correlation between iris pigmentation and eyelash growth (33). Bimatoprost $0.03 \%$, which was further commercialized, has a more substantial effect on eyelash growth than latanoprost. In fact, Noecker et al., in a six-month randomized clinical trial that compared the effects bimatoprost and latanoprost on adnexa, reported eyelash growth in $10.5 \%$ of patients treated with bimatoprost, and no cases in patients receiving latanoprost (34). Similar results were found in other studies $(35,36)$, which observed that hypertrichosis usually appears earlier in bimatoprost compared to latanoprost users. Prostaglandin receptors are present in the dermal papilla and the outer root sheath of the hair follicle; the effects of PGAs on eyelashes have been hypothesized to be induced by a prolonged eyelash anagen phase, which is the active growth phase (37). mRNAs for prostaglandin receptors were expressed in the dermal papilla cells and the outer-root sheath cells located in the hair bulb region in the anagen phase; however, these signals disappeared in the telogen phase (38).

The cutaneous bio disposition of bimatoprost was also investigated in mise at three different concentrations $(0.01 \%$, $0.03 \%$ and $0.06 \%$ ) (39). The results indicated that the cutaneous levels of bimatoprost is dose-dependent and is well maintained over a 1-day period. Furthermore, bimatoprost remains in the skin as an intact molecule, indicating a prostamide receptor involvement. Because of the effects on eyelash growth bimatoprost $0.03 \%$ solution has been purposed for treating hypotrichosis of the eyelashes (40); the average eyelash growth after three months of treatment is $1.4-2 \mathrm{~mm}$, a statistically significant difference.
Meibomian glands (MGs) disfunction. MGs are holocrine glands embedded in the tarsal plate of the eyelids, and produce meibum. Meibometry and non-contact meibography demonstrated that antiglaucoma drugs induce morphological changes and dysfunction of MGs, leading to dry eye. Particularly, MG loss and low secretion expressibility are some of the most common features in preserved antiglaucoma drugs users; preserved PGAs and preserved $\beta$ blockers, which are the most widely used medications to treat glaucoma, induce a similar significant involution of Meibomian lipoid activity, which correlates with BUT reduction and ocular surface symptoms (41-43). These results introduced the question of whether MGs modifications are induced by preservatives, active components, or both. By means of IVCM, Agnifili et al. (44) investigated the $\mathrm{MG}$ features in medically controlled glaucoma treated with preserved or preservative-free (PF) drugs, observing a significant reduction of the mean acinar density (MAD) and area (MAA), a greater secretion reflectivity, and a higher interstice inhomogeneity in preserved PGA users. The comparison of preserved and PF agents showed that preserved PGAs were more toxic than PF-PGAs (Figure 1). Lower MAD and MAA values were considered expressions of glandular loss and reduced meibum production, respectively, and the inhomogeneity of interstice as a sign of tarsum and MGs inflammation, suggesting that PGAs play a pivotal role in inducing $\mathrm{MG}$ alterations in medically controlled glaucomatous patients. The authors suggested that the presence of preservatives enhances the effect of PGAs either through a direct toxic 
effect on MGs or promoting the drug's penetration into the glands. Recently the association between PGAs and MG dysfunction (MGD) has been confirmed in a clinical study (45), in which the prevalence of MGD was higher in patients treated with PGA $(92.0 \%)$ compared with those receiving non-PGA therapy $(58.3 \%)$; in addition, patients treated with PGAs presented the obstructive type of MGD (95.7\%).

\section{Ocular surface changes}

Conjunctival epithelium and Goblet cells (GCs) modification. The presence of conjunctival epithelial desquamation, inflammation, apoptosis, and hyperemia is rarely described in PF beta-blockers and PF PGA, but is frequently reported in corresponding preserved formulations (46). GCs are the main source of ocular surface mucoproteins, with their number progressively decreasing with aging; they are extremely sensitive irritating stimuli and their loss leads to dry eye, conjunctival inflammation and fibrosis. Recently, the density of preoperative GCs was correlated with the filtration with the surgical outcome of trabeculectomy $(47,48)$, therefore, the preservation of GCs represents a crucial factor for surgical success. Goblet cells density (GCD) was found to change especially in PGAs treated eyes. Several studies showed that GCs and mucin marker were reduced after long-term therapy with preservative drugs (47) (Figure 2), and also in patients receiving either PF-PGAs or PF-beta blockers (49, 50). Conversely, Russ et al. (51) found a transient increase in GCD in patients treated with preserved PGAs, followed by a density reduction after longer periods of treatment. In accordance with these initial evidence, Mastropasqua et al. (52) observed a short-term favourable effect of PF-tafluprost on GCs, documenting a persistent increase of GCD 6 months after initiating therapy. Differently, in patients receiving preserved latanoprost, GCD increased after 1 month, whereas reduced to baseline values after 6 months. These results suggested that PF-PGAs may have a potentially positive effect on GCs with respect to the preserved PGAs, in which the balance between the toxicity of preservative and stimulation of PGAs induces a long-term loss of GCs.

Conjunctival epithelial microcysts (CEM) modification. Conjunctiva generally shows CEM, that appear as dark, round or oval-shaped structures, located below the epithelium. The presence of CEM were described in untreated ocular hypertension $(\mathrm{OH})$, in medically treated open glaucoma (Figure 3) and after filtration surgery (53-57). In a study with IVCM and immune-histology of the aqueous humor after trabeculectomy, Amar et al. (58) hypothesized that CEM observed in functioning blebs correspond to modified conjunctival GCs that may work as aqueous humor carriers.

The analysis of the relationship between CEM and PGAs shows conflicting results. Eyes treated with unfixed

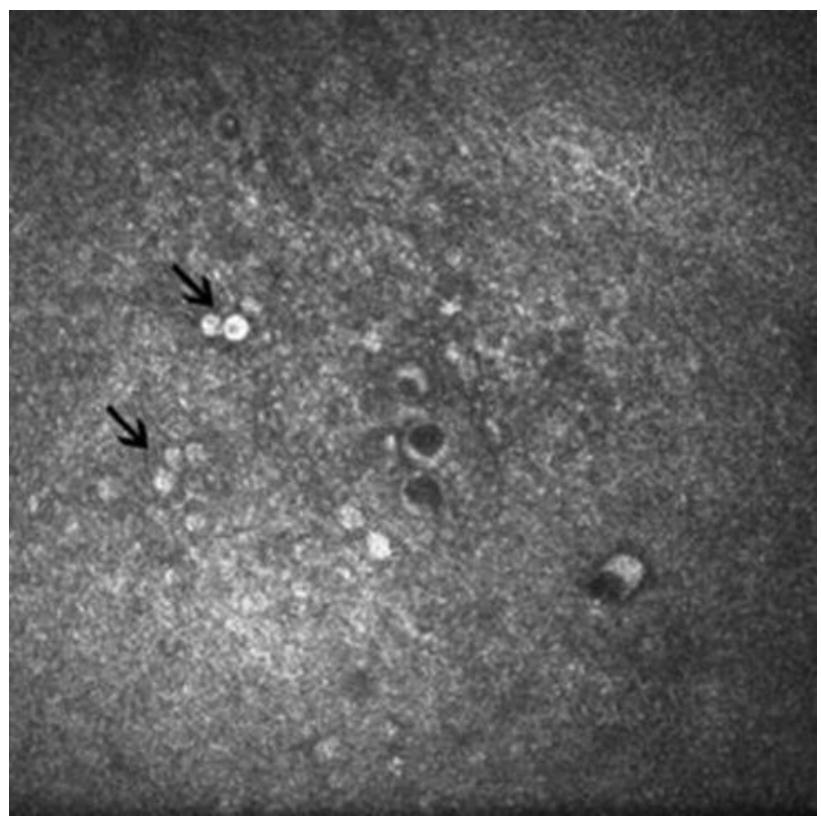

Figure 2. Reduction of Goblet cells density in patient receiving preserved PGAs. Arrows indicate clusters of goblet cells dispersed within the epithelium.

combination therapy (beta-blocker/PGAs) showed a significantly greater mean microcyst density (MMD) and larger mean microcyst area (MMA) compared to eyes on single drug therapy (preserved PGAs or preserved $\beta$-blocker) (59). In naive patients, both PF PGAs and preserved PGAs increased MMA (by half and two-fold, respectively) after 3 months of therapy, without MMD modification (60). This suggested that PGAs increased the trans-conjunctival aqueous humor outflow by enhancing pre-existing intraconjunctival pathways rather than inducing novel pathways, and that benzalkonium chloride may account for a higher drug efficacy on aqueous humour outflow. This is consistent with the mechanism of action of PGAs and confirmed an ex vivo study on human conjunctiva where Terai et al. (61) documented an enlarged sub-epithelial empty spaces after PGA exposure.

Conjunctiva-associated lymphoid tissue (CALT). The conjunctiva-associated lymphoid tissue (CALT), which represents the conjunctival part of the eye-associated lymphoid tissues (EALT), develops within the tarsal and bulbar conjunctiva, forming the immunological interface between the ocular surface and the external environment (62, 63). CALT presents specialized functions since the activities developed by immune mucosal tissue are functionally adapted to the ocular surface: because of this, CALT 


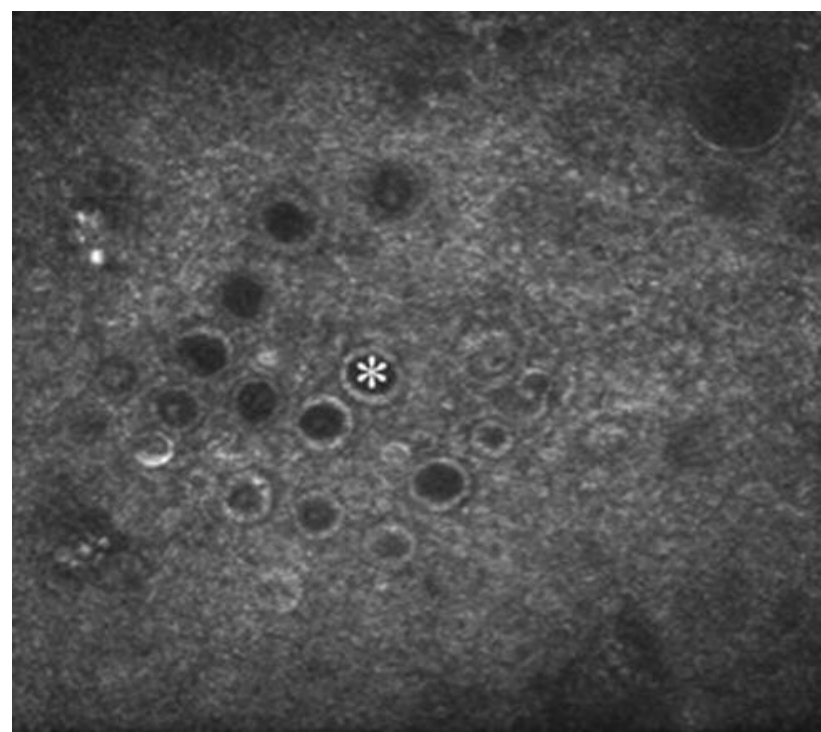

Figure 3. Epithelial microcysts in patient treated with PF. PGAs appear as dark, round or oval-shaped structures (asterisk), sometimes clustered, below the conjunctival epithelium.

promotes corneal immune protection and is responsible for the generation of the immune tolerance against environmental nonpathological antigens making contact with the ocular surface. The effect of glaucoma therapy on CALT has been suspected by lymphocyte and plasma cells infiltration in the substantia propria of the conjunctiva, by hypertrophy or formation of new conjunctival follicles, and by the occurrence of follicular conjunctivitis in medically controlled glaucoma. In an in vivo confocal study on rabbits, it was observed that the administration of preserved PGAs induced infiltration of hyper-reflective inflammatory cells in the para-follicular area with a linear correlation between the degree of cellular infiltration and concentration of preservative (46). The role of preservative in the CALT stimulation was further confirmed in a different rabbit study where, while preserved PGAs induced an intra-follicular infiltration of inflammatory cells (according to their BAK concentration) PF latanoprost did not induce inflammatory changes. These findings suggested a pivotal role of BAK over active compounds in activating the conjunctival immune cells (64). In human eyes, Mastropasqua et al. (55, 65) reported CALT modifications similar to those observed in rabbits. Particularly, after 3-months, therapy-naïve glaucomatous patients receiving preserved latanoprost showed inflammatory cells infiltrating follicles and interfollicular spaces; in contrast, patients treated with $\mathrm{PF}$ tafluprost did not show inflammatory signs. Notably, the follicular architecture in treated eyes also showed structural

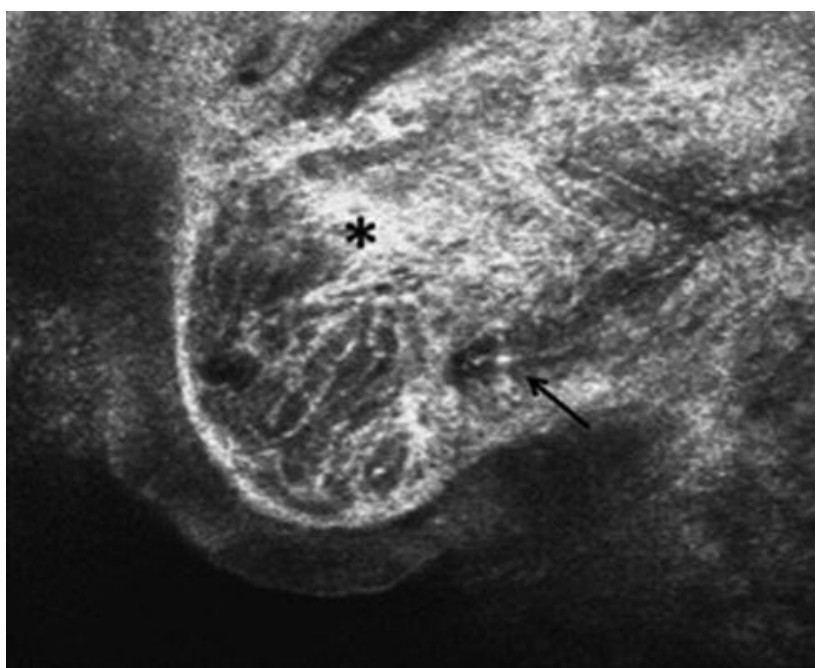

Figure 4. In vivo confocal microscopy of human conjunctiva-associated lymphoid tissue after a long-term therapy with PF-PGAs. Presumed follicles appear as roundish or oval-shaped structures composed of a network of collagen fibrils with an increased reflectivity because of core fibrosis (asterisk), hosting some hyper-reflective elements corresponding to immune cells (arrow).

alterations due to collagen accumulation, since the reticular connective pattern of the core appeared more prominent and hyper-reflective (Figure 4).

Corneoscleral limbus $(C L)$. The $\mathrm{CL}$ is one of the main components composing the ocular surface unit, and exerts a crucial role in the maintenance of the corneal epithelial integrity because hosts the niches for corneal epithelial stem cells. The CL integrity may be altered by several factors, such as inflammatory diseases, corneal burns, contact wear lens and topical medications. The effect of antiglaucoma drugs on CL was first hypothesized by Schwartz and Holland (66), who described limbal stem cell deficiency in glaucomatous eyes who underwent ocular surgery of the CL. Recently, IVCM and impression cytology have been used in diagnosis of limbal stem cell deficiency $(67,68)$. The effects of BAK preserved latanoprost, BAK $0.02 \%$, and PF tafluprost in rabbits were investigated by Liang et al. (46). The authors found inflammatory cells infiltrating the limbal area in eyes receiving preserved latanoprost or BAK alone, whereas rabbit treated with PF tafluprost did not show CL changes. These results were further confirmed by Pauly et al. (69) in a study in which limbal inflammatory cells were rarely observed in eyes treated with PF-latanoprost group, but markedly infiltrated CL and peripheral cornea in eyes exposed to $0.02 \%$ BAK or and BAK-preserved latanoprost. Only few studies aimed at evaluating CL were conducted in humans; these studies used IVCM to investigate the effects 


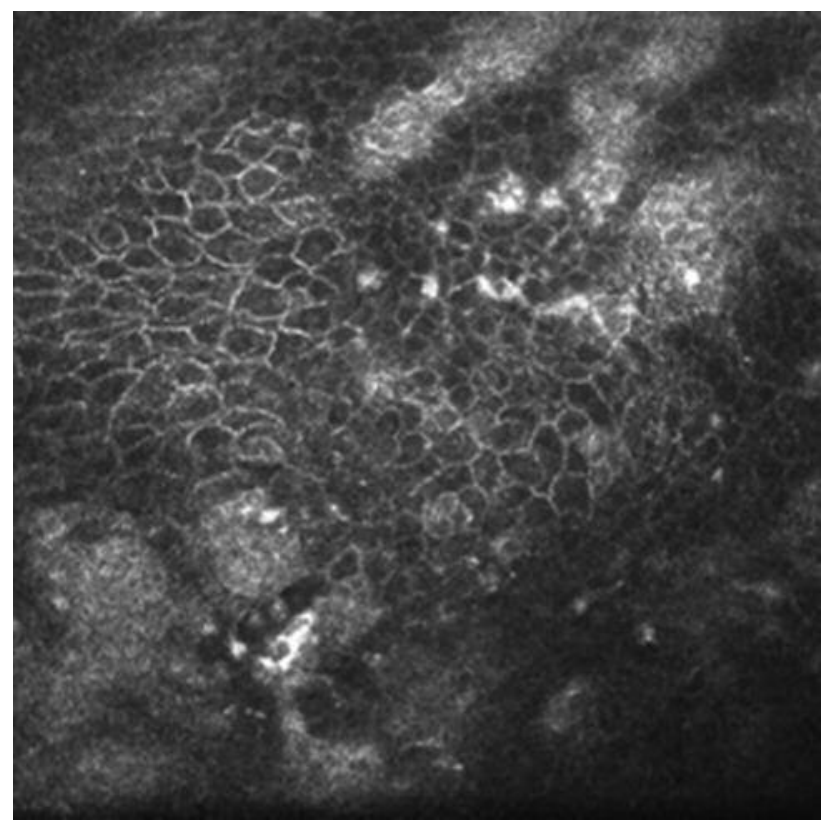

Figure 5. Limbal transmission epithelium in PF-PGAs. The normal architecture of the LTE is preserved, even though the epithelium shows an increased reflectivity and some punctate reflective elements.

of IOP lowering medications analysing the morphology of the limbal transition epithelium (LTE, Figure 5) and palisades of Vogt (POV), and the density of dendritic cells (DCs) $(70,71)$. LTE showed worse regularity in patients controlled with preserved PGAs or preserved beta-blockers, whereas did not show severe changes in patients treated with PF drugs. The most important change was found on DCs, which presented a higher density in patients taking preserved PGAs or beta-blockers compared with patients treated with PF formulations (Figure 6). Moreover, PF PGAs showed a similar DC density compared with PF beta-blockers. This result indicates the corneal inflammatory status increases in glaucomatous patients treated PGAs, particularly at limbus; however, the absence of significant differences between preserved PGA and preserved beta-blockers or between PF PGA and PF b-blockers, does not allow us to determine whether the preservative or the active compound plays the main role in the final DC increase. By critically analysing data, both preservative and active compounds cooperate in recruiting DCs, because preserved PGA produced the highest degree of DCs stimulation. Finally, palisades of Vogt showed punctate reflecting elements in PGAs users, this indicating a deep drug-induced inflammation.

Corneal epithelial modifications. In an in vitro study of corneal epithelium, Pauly et al. found that while $0.02 \%$ BAK

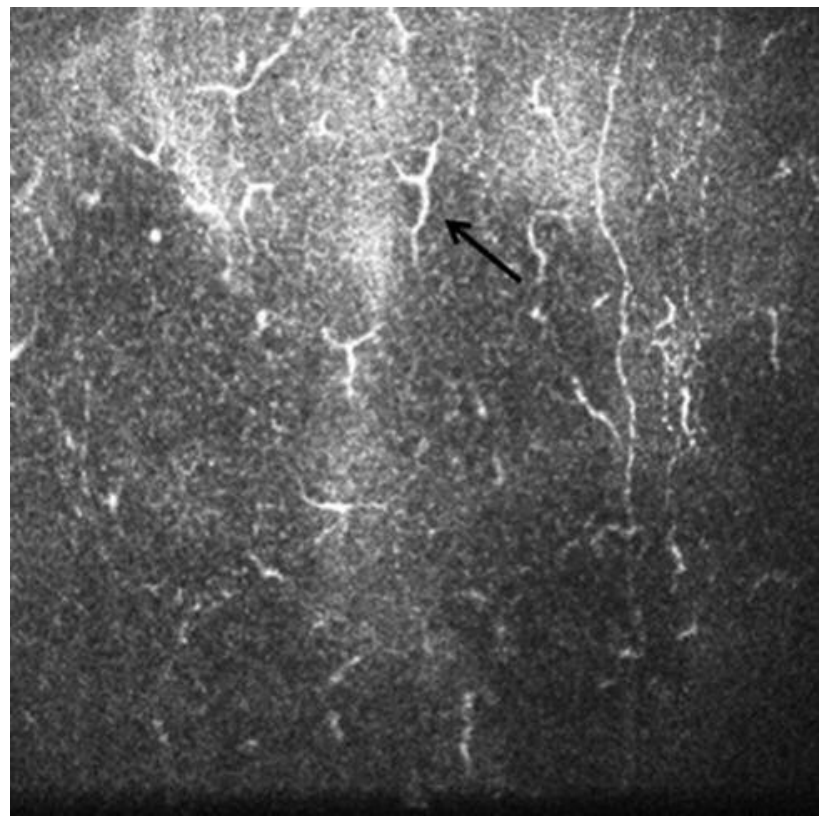

Figure 6. Dendritic cells at the limbus in preserved PGAs (arrow). Patients treated with preserved PGAs present an increase of DCs density.

and BAK preserved-latanoprost decreased the cell viability to about $50 \%$ by inducing apoptosis of apical layers of the epithelium, PF-latanoprost slightly decreased cell viability to $83 \%$ with few relatively apoptotic cells (69). Also, an in vivo study by Martone et al. (72) confirmed the reduction of corneal innervation in the superficial epithelium in patients treated with preserved formulations, without difference between PGAs and other drugs. These changes were interpreted as a direct toxic effect of BAK on the epithelium, rather than effects of active compounds.

Corneal stroma and endothelial changes. Stromal keratocyte activation was observed in patients treated with betablockers/PGA unfixed combination therapy and was hypothesized to be an effect of inflammation, apoptosis and increased proteolytic activity. Bergonzi et al. (73) reported similar results, documenting an increase of the keratocyte density in PGA users, especially in the anterior corneal layer. The authors indicated that the increase of keratocyte density is linked to extracellular collagen degradation, due to activation of metalloproteinases and inhibition of tissue inhibitors of metalloproteinases. Alterations of the number and density of sub-basal plexus nerves $(74,75)$, bead-like formations, along with increased nerve tortuosity were additional stromal features that were more pronounced in patients receiving preserved drugs (Figure 7). In fact, the use 


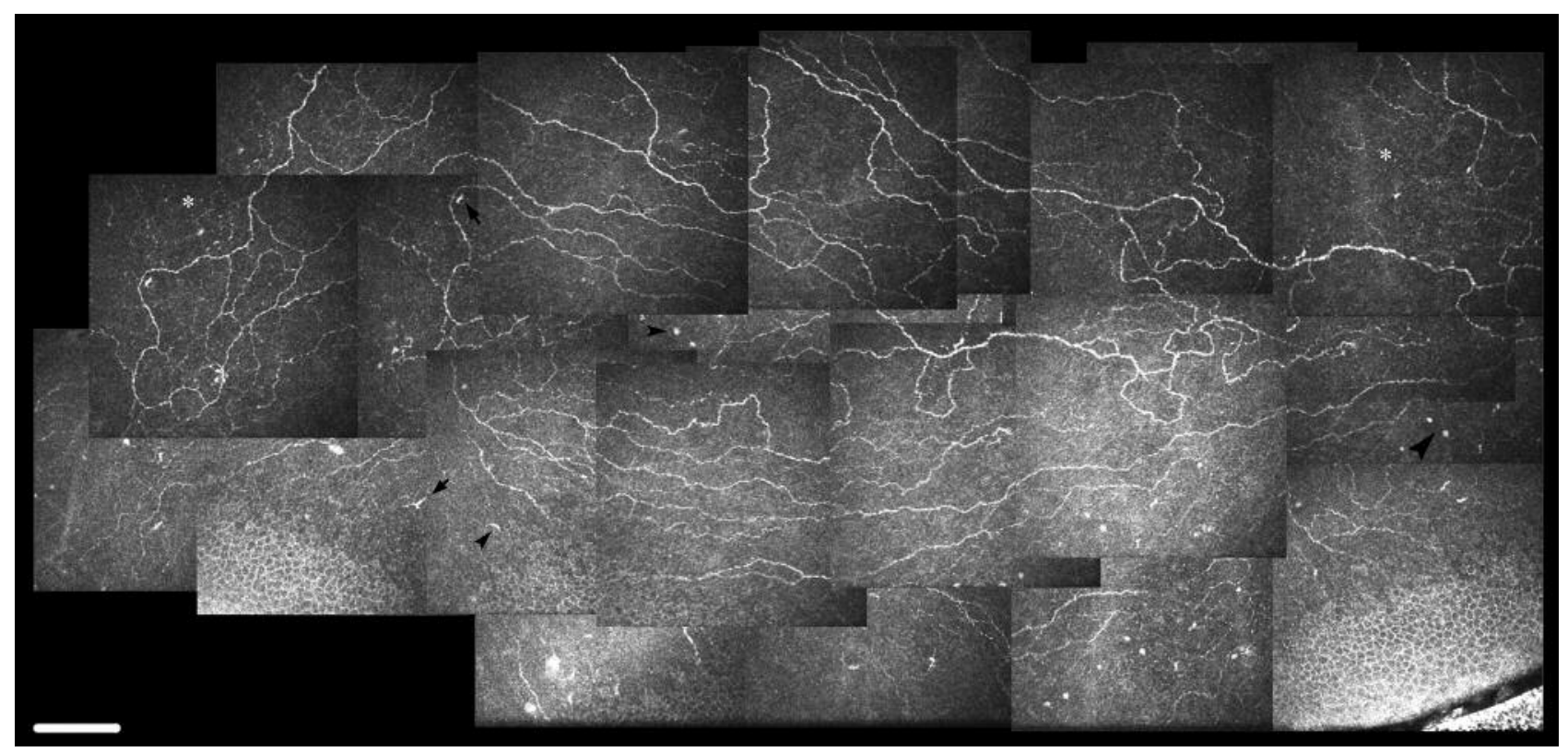

Figure 7. Morphology of sub-basal plexus nerves in patient receiving preserved PGAs. Nerve tortuosity and bead-like formations are found.

of PF tafluprost did not induce modifications of epithelial cells or keratocyte activation, and did not modify the number of sub-basal nerves or the grade of nerve tortuosity. Ranno et al. investigated the anterior and posterior corneal features (76), focusing on corneal nerve fiber and endothelial cell density in eyes treated with beta-blockers and PGAs for at least two years. A significant difference was found in nerve fiber number, tortuosity, reflectivity, and endothelial cell density in treated eyes compared to controls and naïve to therapy glaucomatous patients. The intraclass analysis revealed that PGAs and beta-blockers had similar results for nerve number, tortuosity, reflectivity or number of endothelial cells. This study is the first that documented a lower endothelium density in patients receiving PGAs.

\section{Conclusion}

In closing, PGAs induce several modifications of ocular surface and adnexa, that can be recognized in vivo and in vitro, but none reduces the overall safety profile of this class of drugs. Moreover, the changes in the ocular surface do not modify the IOP lowering efficacy of PGAs. The periocular changes are due to an accumulation of PGAs as the intact molecule, is dose-dependent, and is mediated by stimulation of FP receptors. Furthermore, they are almost in part reversible when the patients are shifted to PF-PGAs. GCs and CEM modifications are consistent with the mechanism of action of PGAs, which enhance trans-scleral and trans- conjunctival outflow by remodeling the extracellular matrix and tissue permeability. Conversely, corneal changes are more likely due to the inflammatory effects of PGAs. In PFPGAs users, the negative toxic effects induced by preservatives are strongly reduced, this highlighting the main role of preservatives, thus, supporting the choice of PF-PGAs for long-term therapies.

\section{References}

1 Quigley HA and Broman AT: The number of people with glaucoma worldwide in 2010 and 2020. Br J Ophthalmol 90: 262-267, 2006.

2 Virno M, Sampaolesi R, Pecori Giraldi J, De Gregorio F, Taloni M, Brusini P, Di Staso S and Stecchi G: Ibopamine: D1dopaminergic agonist in the diagnosis of glaucoma. J Glaucoma 22: 5-9, 2013.

3 Fajgenbaum M and Ansari E: Prescribing Trends in a Glaucoma Clinic and Adherence to EGS Guidelines: A Retrospective, NonInterventional, Single-Center UK Study. Adv Ther 34: 20332044, 2017.

4 Mastropasqua R, Fasanella V, Agnifili L, Fresina M, Di Staso S, Di Gregorio A, Marchini G and Ciancaglini M: Advance in the pathogenesis and treatment of normal-tension glaucoma. Prog Brain Res 221: 213-232, 2015.

5 Sena DF and Lindsley K: Neuroprotection for treatment of glaucoma in adults. Cochrane Database Syst Rev 25: 1, 2017.

6 Chiosi F, Keppel Hesselink J, Rinaldi M, Di Staso S, Bartollino $\mathrm{S}$ and Costagliola $\mathrm{C}$ : Phenytoin: its potential as neuroprotective and retinoprotective drug. Br J Clin Pharmacol 84: 195-196, 2017. 
7 Baudouin C, Hamard P, Liang H, Creuzot-Garcher C, Bensoussan L and Brignole F: Conjunctival epithelial cell expression of interleukins and inflammatory markers in glaucoma patients treated over the long term. Ophthalmology 111: 2186-2192, 2004.

8 Villani E, Sacchi M, Magnani F, Nicodemo A, Williams SE, Rossi A, Ratiglia R, De Cillà S and Nucci P: The ocular surface in medically controlled glaucoma: an in vivo confocal study. Invest Ophthalmol Vis Sci 57: 1003-1010, 2016.

9 Peplinski LS and Albiani Smith K: Deepening of lid sulcus from topical bimatoprost therapy. Optom Vis Sci 81: 574-577, 2004.

10 Yang HK, Park KH, Kim TW and Kim DM: Deepening of eyelid superior sulcus during topical travoprost treatment. Jpn J Ophthalmol 53: 176-179, 2009.

11 Nakakura S, Tabuchi $\mathrm{H}$ and Kiuchi Y: Latanoprost therapy after sunken eyes caused by travoprost or bimatoprost. Optom Vis Sci 88: 1140-1144, 2011

12 Inoue $\mathrm{K}$, Shiokawa M, Wakakura M and Tomita G: Deepening of the upper eyelid sulcus caused by 5 types of prostaglandin analogs. J Glaucoma 22: 626-631, 2013.

13 Sakata R, Shirato S, Miyata K and Aihara M: Incidence of deepening of the upper eyelid sulcus on treatment with a tafluprost ophthalmic solution. Jpn J Ophthalmol 58: 212-217, 2014.

14 Patradul C, Tantisevi V and Manassakorn A: Factors related to prostaglandin-associated periorbitopathy in glaucoma patients Asia-Pac J Ophthalmol 6: 238-242, 2017.

15 Aihara M, Shirato S and Sakata R: Incidence of deepening of the upper eyelid sulcus after switching from latanoprost to bimatoprost. Jpn J Ophthalmol 55: 600-604, 2011.

16 Maruyama K, Tsuchisaka A, Sakamoto J, Shirato S and Goto H: Incidence of deepening of upper eyelid sulcus after topical use of tafluprost ophthalmic solution in Japanese patients. Clin Ophthalmol 7: 1441-1446, 2013.

17 Maruyama K, Shirato $S$ and Tsuchisaka A: Incidence of deepening of the upper eyelid sulcus after topical use of travoprost ophthalmic solution in Japanese. J Glaucoma 23: 160163,2014

18 Sakata R, Shirato S, Miyata K and Aihara M: Recovery from deepening of the upper eyelid sulcus after switching from bimatoprost to latanoprost. Jpn J Ophthalmol 57: 179-184, 2013.

19 Tan J and Berke S: Latanoprost-induced prostaglandinassociated perior $\neg$ bitopathy. Optom Vis Sci 90: 245-247, 2013.

20 Yoshino T, Fukuchi T, Togano T, Seki M, Ikegaki H and Abe H: Eyelid and eyelash changes due to prostaglandin analog therapy in unilateral treatment cases. Jpn J Ophthalmol 57: 172-178, 2013.

21 Jayaprakasam A and Ghazi-Nouri S: Periorbital fat atrophy, an unfamiliar side effect of prostaglandin analogues. Orbit 29: 357359,2010 .

22 Taketani Y, Yamagishi R, Fujishiro T, Igarashi M, Sakata R and Aihara M: Activation of the prostanoid FP receptor inhibits adipogenesis leading to deepening of the upper eyelid sulcus in prostaglandin-associated periorbitopathy. Invest Ophthalmol Vis Sci 55: 1269-1276, 2014.

23 Elgin U, Batman A, Berker N and Ilhan B: The comparison of eyelashes lengthening effect of latanoprost therapy in adults and children. Eur J Ophthalmol 16: 247-250, 2006.

24 Sharpe ED, Reynolds AC, Skuta GL, Jenkins JN and Stewart WC: The clinical impact and incidence of periocular pigmentation associated with either latanoprost or bimatoprost therapy. Cur Eye Res 32: 1037-1043, 2007.
25 Parrish RK, Palmberg P and Sheu W-P: A comparison of latanoprost, bimatoprost, and travoprost in patients with elevated intraocular pressure: a 12-week, randomized, maskedevaluator multicenter study. Am J Ophthalmol 135: 688-703, 2003.

26 Kampik A, Arias-Puente A, O'Brart DPS and Vuori M: The European latanoprost study group. Intraocular pressure lowering effects of latanoprost and brimonidine therapy in patients with open-angle glaucoma or ocular hypertension:a randomized observer-masked multicenter study. J Glaucoma 11: 90-96, 2002.

27 Birt CM, Buys YM, Ahmed IIK and Trope GE: The Toronto area glaucoma society. Prostaglandin efficacy and safety study undertaken by race (the pressure study). J Glaucoma 19: 460467, 2010.

28 Inoue $\mathrm{K}$, Wakakura $\mathrm{M}$, Inoue $\mathrm{J}$, Matsuo $\mathrm{H}$, Hara $\mathrm{T}$ and Tomita G: Adverse reactions after use of latanoprost in Japanese glaucoma patients. Nippon Ganka Gakkai Zasshi 110: 581-587, 2006.

29 Inoue K, Shiokawa M, Sugahara M, Higa R, Wakakura M and Tomita G: Iris and periocular adverse reactions tobimatoprost in Japanese patients with glaucoma or ocular hypertension. Clin Ophthalmol 6: 111-116, 2012.

30 Chiba T, Kashiwagi K, Ishijima K, Furuichi M, Kogure S, Abe $\mathrm{K}$, Chiba $\mathrm{N}$ and Tsukahara S: A prospective study of iridial pigmentation and eyelash changed due to ophthalmic treatment with latanoprost. Jpn J Ophthalmol 48: 141-147, 2004.

31 Inoue K, Shiokawa M, Higa R, Sugahara M, Soga T, Wakakura $\mathrm{M}$ and Tomita G: Adverse periocular reactions to five types of prostaglandin analogs. Eye 26: 1465-1472, 2012.

32 Johnstone MA: Hypertrichosis and increased pigmentation of eyelashes and adjacent hair in the region of the ipsilateral eyelids of patients treated with unilateral topical latanoprost. Am J Ophthalmol 124: 544-547, 1997.

33 Chiba T, Kashiwagi K, Ishijima K, Furuichi M, Kogure S, Abe $\mathrm{K}$, Chiba $\mathrm{N}$ and Tsukahara $\mathrm{S}$ : A prospective study of iridial pigmentation and eyelash changes due to ophthalmic treatment with latanoprost. Jpn J Ophthalmol 48: 141-147, 2004.

34 Noecker RS, Dirks MS, Choplin NT, Bernstein P, Batoosingh $\mathrm{AL}$ and Whitcup SM: The Bimatoprost/Latanoprost Study Group. A six-month randomized clinical trial comparing the intraocular pressure-lowering efficacy of bimatoprost and latanoprost in patients with ocular hypertension or glaucoma. Am J Ophthalmol 135: 55-63, 2003.

35 Eisenberg DL, Toris CB and Camras CB: Bimatoprost and travoprost: a review of recent studies of two new glaucoma drugs. Surv Ophthalmol 47: S105-115, 2002.

36 Tosti A, Pazzaglia M Voudouris S and Tosti G: Hypertrichosis of the eyelashes caused by bimatoprost. J Am Acad Dermatol 51: S149-150, 2004.

37 Nesher R, Mimouni M, Elnaddaf H, Nemet A and Kidron D: Characterization of prostaglandin $\mathrm{F} 2 \alpha$ receptors in human eyelids. Eur J Ophthalmol 25: 81-84, 2015.

38 Torii E, Segi E, Sugimoto Y, Takahashi K, Kabashima K, Ikai K and Ichikawa A: Expression of prostaglandin E(2) receptor subtypes in mouse hair follicles. Biochem Biophys Res Commun 290: 696-700, 2002.

39 Woodward DF, Tang ES, Attar M and Wang JW: The biodisposition and hypertrichotic effects of bimatoprost in mouse skin. Experimental Dermatology 22: 141-159, 2013. 
40 Wester ST, Lee WW and Shi W: Eyelash growth from application of bimatoprost in gel suspension to the base of the eyelashes. Ophthalmology 117: 1024-1031, 2010.

41 Cunniffe MG, Medel-Jiménez R and González-Candial M: Topical antiglaucoma treatment with prostaglandin analogues may precipitate meibomian gland disease. Ophthal Plast Reconstr Surg 27: 28-29, 2011.

42 Arita R, Itoh K, Maeda S, Maeda K, Furuta A, Tomidokoro A, Aihara $\mathrm{M}$ and Amano S: Comparison of the long-term effects of various topical antiglaucoma medications on meibomian glands. Cornea 31: 1229-1234, 2012.

43 Arita R, Itoh K, Maeda S, Maeda K, Furuta A, Tomidokoro A, Aihara $\mathrm{M}$ and Amano S: Effects of long-term topical antiglaucoma medications on meibomian glands. Graefes Arch Clin Exp Ophthalmol 250: 1181-1185, 2012.

44 Agnifili L, Fasanella V, Costagliola C, Ciabattoni C, Mastropasqua $\mathrm{R}$, Frezzotti $\mathrm{P}$ and Mastropasqua L: In vivo confocal microscopy of meibomian glands in glaucoma. Br J Ophthalmol 97: 343-349, 2013.

45 Mocan MC, Uzunosmanoglu E, Kocabeyoglu S, Karakaya J and Irkec M: The association of chronic topical prostaglandin analog use with Meibomian gland dysfunction. Eur J Ophthalmol 25: 38-39, 2015.

46 Liang H, Baudouin C, Pauly A and Brignole-Baudouin F: Conjunctival and corneal reactions in rabbits following short- and repeated exposure to preservative-free tafluprost, commercially available latanoprost and $0.02 \%$ benzalkonium chloride. $\mathrm{Br} \mathrm{J}$ Ophthalmol 92: 1275-1282, 2008.

47 Agnifili L, Fasanella V, Mastropasqua R, Frezzotti P, Curcio C, Brescia L and Marchini G: In vivo goblet cell density as a potential indicator of glaucoma filtration surgery outcome. Invest Ophthalmol Vis Sci 57: 2898-2905, 2016.

48 Mastropasqua R, Fasanella V, Brescia L, Oddone F, Mariotti C, Di Staso $\mathrm{S}$ and Agnifili L: In vivo confocal imaging of the conjunctiva as a predictive tool for the glaucoma filtration surgery outcome. Invest Ophthalmol Vis Sci 58: 114-120, 2017

49 Pisella PJ, Debbasch C, Hamard P, Creuzot-Garcher C, Rat P, Brignole $\mathrm{F}$ and Baudouin $\mathrm{C}$ : Conjunctival proinflammatory and proapoptotic effects of latanoprost and preserved and unpreserved timolol: an ex vivo and in vitro study. Invest Ophthalmol Vis Sci 45: 1360-1368, 2004

50 Kahook MY and Noecker R: Quantitative analysis of conjunctival goblet cells after chronic application of topical drops. Adv Ther 25: 743-751, 2008.

51 Russ HH, Costa VP, Ferreira FM, Valgas SR, Correa Neto MA, Strobel Ev and Truppel JH: Conjunctival changes induced by prostaglandin analogues and timolol maleate: a histomorphometric study. Arq Bras Oftalmol 70: 910-916, 2007.

52 Mastropasqua L, Agnifili L, Fasanella V, Curcio C, Ciabattoni C, Mastropasqua R, Toto L and Ciancaglini M: Conjunctival goblet cells density and preservative free tafluprost therapy for glaucoma: An in vivo confocal microscopy and impression cytology study. Acta Ophthalmol 91: 397-405, 2013.

53 Ciancaglini M, Carpineto P, Agnifili L, Nubile M, Lanzini M, Fasanella V and Mastropasqua L: Filtering bleb functionality: a clinical, anterior segment optical coherence tomography and in vivo confocal microscopy study. J Glaucoma 17: 308-317, 2008.

54 Agnifili L, Carpineto P, Fasanella V, Mastropasqua R, Zappacosta A, Di Staso S, Costagliola C and Mastropasqua L: Conjunctival findings in hyperbaric and low-tension glaucoma: an in vivo confocal microscopy study. Acta Ophthalmol 90: 132-137, 2012.
55 Mastropasqua L, Agnifili L, Mastropasqua R, Fasanella V, Nubile M, Toto L, Carpineto $\mathrm{P}$ and Ciancaglini M: In vivo laser scanning confocal microscopy of the ocular surface in glaucoma. Microsc Microanal 20: 879-894, 2014.

56 Mastropasqua R, Agnifili L, Fasanella V, Toto L, Brescia L, Di Staso S, Doronzo E and Marchini G: Uveo-scleral outflow pathways after ultrasonic cyclocoagulation in refractory glaucoma: an anterior segment optical coherence tomography and in vivo confocal study. Br J Ophthalmol 100: 1668-1675, 2016.

57 Di Staso S, Agnifili L, DI Gregorio A, Climastone H, Galassi E, Fasanella V and Ciancaglini M: Three-dimensional laser scanning confocal analysis of conjunctival microcysts in glaucomatous patients before and after trabeculectomy. In Vivo 31: 1081-1088, 2017.

58 Amar N, Labbè A, Hamard P, Dupas B and Baudouin C: Filtering blebs and aqueous pathway. An immunocytological and in vivo confocal microscopy study. Ophthalmology 115: 11541161,2008

59 Ciancaglini M, Carpineto P, Agnifili L, Nubile M, Fasanella V and Mastropasqua L: Conjunctival modifications in ocular hypertension and primary open angle glaucoma: An in vivo confocal microscopy study. Invest Ophthalmol Vis Sci 49: 30423048,2008

60 Mastropasqua R, Fasanella V, Pedrotti E, Lanzini M, Di Staso S, Mastropasqua L and Agnifili L: Trans-conjunctival aqueous humor outflow in glaucomatous patients treated with prostaglandin analogues: an in vivo confocal microscopy study. Graefes Arch Clin Exp Ophthalmol 252: 1469-1476, 2014.

61 Terai N, Schlötzer-Schrehardt U, Lampel J, Böhm AG, Rummelt C, Schmidt E and Pillunat LE: Effect of latanoprost and timolol on the histopathology of the human conjunctiva. $\mathrm{Br} \mathrm{J}$ Ophthalmol 93: 219-224, 2009.

62 Siebelmann S, Gehlsen U, Hüttmann G, Koop N, Bölke T, Gebert A, Stern ME, Niederkorn JY and Steven P: Development, alteration and real time dynamics of conjunctiva-associated lymphoid tissue. PLoS One 8: e82355, 2013.

63 Agnifili L, Mastropasqua R, Fasanella V, Di Staso S, Mastropasqua A, Brescia L and Mastropasqua L: In vivo confocal microscopy of conjunctiva-associated lymphoid tissue in healthy humans. Invest Ophthalmol Vis Sci 55: 5254-5262, 2014.

64 Liang, H, Baudouin C, Faure MO, Lambert G and BrignoleBaudouin: Comparison of the ocular tolerability of a latanoprost cationic emulsion versus conventional formulations of prostaglandins: An in vivo toxicity assay. Mol Vis 15: 1690$1699,2009$.

65 Mastropasqua R, Agnifili L, Fasanella V, Nubile M, Gnama AA, Falconio G, Perri P, Di Staso S and Mariotti C: The ConjunctivaAssociated Lymphoid Tissue in Chronic Ocular Surface Diseases. Microsc Microanal 23: 697-707, 2017.

66 Schwartz GS and Holland EJ: Iatrogenic limbal stem cell deficiency. Cornea 17: 31-37, 1998.

67 Kojima T, Matsumoto Y, Ibrahim OM, Sato EA, Dogru M and Tsubota K: In vivo evaluation of superior limbic keratoconjunctivitis using laser scanning confocal microscopy and conjunctival impression cytology. Invest Ophthalmol Vis Sci 51: 3986-3992, 2010.

68 Nubile M, Lanzini M, Miri A, Pocobelli A, Calienno R, Curcio C, Mastropasqua R, Dua HS and Mastropasqua L: In vivo confocal microscopy in diagnosis of limbal stem cell deficiency. Am J Ophthalmol 155: 220-222, 2013. 
69 Pauly A, Roubeix C, Liang H, Brignole-Baudouin F and Baudouin C: In vitro and in vivo comparative toxicological study of a new preservative-free latanoprost formulation. Invest Ophthalmol Vis Sci 53: 8172-8180, 2012.

70 Mastropasqua R, Agnifili L, Fasanella V, Curcio C, Brescia L, Lanzini M, Fresina M, Mastropasqua L and Marchini G: Corneoscleral limbus in glaucoma patients: in vivo confocal microscopy and immunocytological study. Invest Ophthalmol Vis Sci 56: 2050-2058, 2015.

71 Mastropasqua R, Agnifili L, Fasanella V, Lappa A, Brescia L, Lanzini M, Oddone F, Perri $\mathrm{P}$ and Mastropasqua L: In vivo distribution of corneal epithelial dendritic cells in patients with glaucoma. Invest Ophthalmol Vis Sci 57: 5996-6002, 2016.

72 Martone G, Frezzotti P, Tosi GM, Traversi C, Mittica V, Malandrini A, Pichierri P, Balestrazzi A, Motolese PA, Motolese I and Motolese E: An in vivo confocal microscopy analysis of effects of topical antiglaucoma therapy with preservative on corneal innervation and morphology. Am J Ophthalmol 147: 725-735, 2009.

73 Bergonzi C, Giani A, Blini M, Marchi S, Luccarelli S and Staurenghi G: Evaluation of prostaglandin analogue effects on corneal keratocyte density using scanning laser confocal microscopy. J Glaucoma 19: 617-621, 2010.
74 Baratz KH, Nau CB, Winter EJ, McLaren JW, Hodge DO, Herman DC and Bourne WM: Effects of glaucoma medications on corneal endothelium, keratocytes, and subbasal nerves among participants in the ocular hypertension treatment study. Cornea 25: 1046-1052, 2006.

75 Rossi GC, Blini M, Scudeller L, Ricciardelli G, Depolo L, Amisano A, Bossolesi L, Pasinetti GM and Bianchi PE: Effect of preservative-free tafluprost on keratocytes, sub-basal nerves, and endothelium: a single-blind one-year confocal study on naïve or treated glaucoma and hypertensive patients versus a control group. J Ocul Pharmacol Ther 29: 821-825, 2013.

76 Ranno T, Fogagnolo P, Rossetti L, Orzalesi N and Nucci P: Changes in corneal parameters at confocal microscopy in treated glaucoma patients. Clin Ophthalmol 5: 1037-1042, 2011.

Received December 13, 2017

Revised January 4, 2018

Accepted January 8, 2018 